\title{
Quantitative structure-property relationship (QSPR) model for predicting acidities of ketones
}

\author{
Yunyun Yuan, Philip D. Mosier, Yan Zhang* \\ Department of Medicinal Chemistry, Virginia Commonwealth University, Richmond, USA; \\ ${ }^{*}$ Corresponding Author: yzhang2@,vcu.edu
}

Received 6 December 2011; revised 17 January 2012; accepted 29 January 2012

\begin{abstract}
Ketones are one of the most common functional groups, and ketone-containing compounds are essential in both the nature and the chemical sciences. As such, the acidities $\left(\mathrm{p} K_{\mathrm{a}}\right)$ of ketones provide valuable information for scientists to screen for biological activities, to determine physical properties or to study reaction mechanisms. Direct measurements of $\mathrm{p} K_{\mathrm{a}}$ of ketones are not readily available due to their extremely weak acidity. Hence, a quantitative structureproperty relationship (QSPR) model that can predict the acidities of ketones and their acidity order is highly desirable. The establishment of an acidity scale in dimethyl sulfoxide (DMSO) solution by Bordwell et al. made such an effort possible. By utilizing the $\mathrm{p} K_{\mathrm{a}}$ values of fortyeight ketones determined in DMSO as the training set, a QSPR model for predicting acidities of ketones was built by stepwise multiple linear regression analysis. The established model showed statistical significance and predictive power $\left(r^{2}=\right.$ $0.91, q^{2}=0.86, s=1.42$ ). Moreover, the QSPR model also gave reasonable acidity predictions for five ketones in an external prediction set that were not included in the model generation phase $\left(r^{2}=0.92, s=1.618\right)$. Overall, the reported QSPR model for predicting acidities of ketones provides a useful tool for both biologists and chemists in understanding the biophysical properties and reaction rates of different classes of ketones.
\end{abstract}

Keywords: QSPR; Acidity; Ketones; Linear Regression

\section{INTRODUCTION}

Ketones play a crucial role in nature. For example, metabolism of carbohydrates, fatty acids and amino acids in humans and most vertebrates generates acetone, acetoacetate and beta-hydroxybutyrate, which are known as ketone bodies in biochemistry. Acetoacetate and betahydroxybutyrate are important fuels for many tissues. For example, it was reported that acetoacetate contributes over $90 \%$ to the energy required for respiration in the sheep heart, $85 \%$ in the sheep kidney cortex and $74 \%$ in the sheep diaphragm [1]. Ketone bodies are also found to have therapeutic values for neurological diseases such as Alzheimer's disease [2,3] and Parkinson's disease [3, 4]. Hasebe and Hauptman et al. have discovered their function in reducing epileptic seizures as well $[5,6]$. Additionally, it was reported that monoacetoacetin (glycerol monoacetoacetate) has the potential to decrease growth of human gastric cancer cells [7].

Being inspired by their imperative role in nature, ketones are also commonly applied scientifically and commercially, especially in the field of chemistry. Not only are they massively produced as solvents in industry, but base-catalyzed condensation reactions with ketones are also employed on a daily base in organic synthesis labs. According to the reaction mechanism, in the presence of a base, the chemoselectivity (relative reaction rates) or regioselectivity (preferred reaction site), is primarily determined by the acidities $\left(\mathrm{p} K_{\mathrm{a}}\right)$ of different ketones, i.e. the acidities of alpha hydrogen atoms at different positions (Figure 1). Since ketones are extremely weak acids, direct measurements of their acidities in hydroxylic solvents seem to be impossible. Although measurements of deuterium exchange rates along with some other methods have determined the equilibrium acidities for a number<smiles>[R]C([R])C(=O)C([R])([R])[R]</smiles>

Figure 1. Alpha hydrogens at different positions may have different acidities due to the effect of different $\mathrm{R}$ group substituents $\left(\mathrm{p} K_{\mathrm{a}}\left(\mathrm{H}_{1}\right) \neq\right.$ $\left.\mathrm{p} K_{\mathrm{a}}\left(\mathrm{H}_{2}\right)\right)$. 
of ketones [8-11], the accuracy and applicability were not very satisfying. The establishment of an acidity scale in dimethyl sulfoxide (DMSO) solution by Bordwell [12] was undoubtedly a milestone in this respect. It provided a large number of $\mathrm{p} K_{\mathrm{a}}$ values for a variety of weak acids in DMSO, including ketones. With these $\mathrm{p} K_{\mathrm{a}}$ values as well as the oxidation potentials of ketones and their conjugate bases, Bordwell et al. were able to predict both the acidities of the radical cations formed from the parent acids [13] and the homolytic bond dissociation energies (BDEs) of their acidic $\mathrm{C}-\mathrm{H}$ bonds [14]. BDEs are very useful in terms of studying reaction mechanisms and assessing stabilities of radicals [15]. Due to its simplicity and general applicability, this method of calculating BDEs is still being used today since it was first introduced about twenty years ago [16].

Several groups have described QSPR models to predict $\mathrm{p} K_{\mathrm{a}}$ values of acids, alcohols, phenols, chlorinated phenols and amines [17-23]. To our knowledge, no such effort has been focused on the acidities of ketones yet. Because ketones are so important both in nature and science and because experimental determination of $\mathrm{p} K_{\mathrm{a}}$ values is an exhausting process, the development of a computational model that can accurately predict their acidities is both valuable and timely. More specifically, by utilizing such a QSPR model, biologists can easily explore a variety of ketones that may carry comparable $\mathrm{p} K_{\mathrm{a}}$ with the aforementioned ketone bodies to address the same diseases based on the concept of "bioisosterism", whereas chemists can predict a reaction mechanism where ketones are involved in order to design a more reliable synthetic route for their target compounds. In this report, we present a quantitative structure-property relationship (QSPR) model to predict acidities of ketones in DMSO. The effects of different functional groups and substitution patterns on their acidity as represented by five descriptors in the model are discussed.

\section{MATERIALS AND METHODS}

\subsection{Data Set}

Fifty-eight ketones with experimental $\mathrm{p} K_{\mathrm{a}}$ data $[16,24$, $25]$ were subjected to initial data screening. Three of the ketones were first discarded to avoid incongruence of data. Among them, two have markedly different structures (one is a quaternary ammonium salt and another is a chromium tricarbonyl complex), while the $\mathrm{p} K_{\mathrm{a}}$ of the third ketone was acquired under different condition. The final set of fifty-five ketones (Figure 2) can be categorized into three groups based on their structures. Group A is composed of aliphatic noncyclic ketones $\mathbf{1}$ - 6. Group $\mathrm{B}$ consists of cyclic ketones 7 - 17. The remaining ketones 18 - 55, which typically contain at least one phenyl ring in their structures and are exocyclic with respect to the ketone, form the group $\mathrm{C}$. Group $\mathrm{C}$ can be further divided into five subgroups: $\mathrm{C} 1, \mathrm{CH}_{3} \mathrm{COCHR}_{1} \mathrm{R}_{2}\left(\mathrm{R}_{1}, \mathrm{R}_{2}\right.$ can be either same or different), 18 - 20; $\mathrm{C} 2, \mathrm{CH}_{3} \mathrm{COR}$ ( $\mathrm{R}$ is substituted or non-substituted aromatic ring), 21 33; $\mathrm{C} 3, \mathrm{PhCOCH}_{2} \mathrm{R}$ ( $\mathrm{R}$ can be either aliphatic or aromatic), 34 - 51; $C 4$, PhCOCHR $R_{2}\left(R_{1}, R_{2}\right.$ can either be independent or form a cyclic ring), $52-54$; C5, 55, which falls into none of the above groups.

In order to evaluate how well a model to be built can predict the acidities of ketones, an external prediction set (PSET) that includes one or more members from each group is considered necessary. The criteria for building such a PSET were: 1) ketones which have either highest (7) or lowest (39) $\mathrm{p} K_{\mathrm{a}}$ values are not eligible for the PSET because a model cannot reliably predict properties out of the range it was built, i.e. extrapolation; 2) the qualified candidates for the PSET should be able to represent at least several of their group members or their counterparts from other groups that share the same moieties in their structures. For example, the effect on alpha hydrogen acidity by replacing one hydrogen atom with a methyl group can be calculated from comparing ketones $\mathbf{3 4}$ and 31. Similarly ketone $\mathbf{5}$ is qualified to enter the PSET as long as ketone 1 remains in the training set (TSET). In other words, those that have unique structures were not considered for inclusion in the PSET. Based on these guidelines and the size of each group, ketone $\mathbf{5}$ from group A, ketone $\mathbf{1 0}$ from group B, and ketones 20, 30, and 35 from group $C$ were selected for the PSET. The remaining fifty ketones were used as the training set to generate the QSPR model.

\subsection{Computational Details}

The structures of the selected fifty-five ketones were sketched and energy-minimized by SYBYL 8.1 [26] using the Tripos Force Filed and Gasteiger-Hückel charges with a $0.05 \mathrm{kcal} /(\mathrm{mol} \times \AA)$ energy termination gradient, dielectric constant $\varepsilon=1.0$, and an $8.0 \AA$ nonbonded interaction (NB) cutoff. Molecular descriptors used for describing the acidity and generating the QSPR equation were calculated for each molecule using MDL QSAR version 2.2.0.365. The stepwise multiple linear regression method was used to build the model. The number of descriptors $(n)$ in the equation was limited to no more than the square root of the number of ketones in the TSET minus $2\left(n \leq(\mathrm{TSET})^{0.5}-2\right)$, which is 5 in this case. The following criteria were considered when selecting the descriptors: 1) higher $F$-statistic value introduced first; 2) absolute $t$-statistic value not less than $3.5 ; 3$ ) descriptors should not be highly correlated with each other (intercorrelation coefficient below 0.7$)$; 4) no descriptors with only a few non-zero (or different) values. 
$\left.\right|_{1} ^{1}$
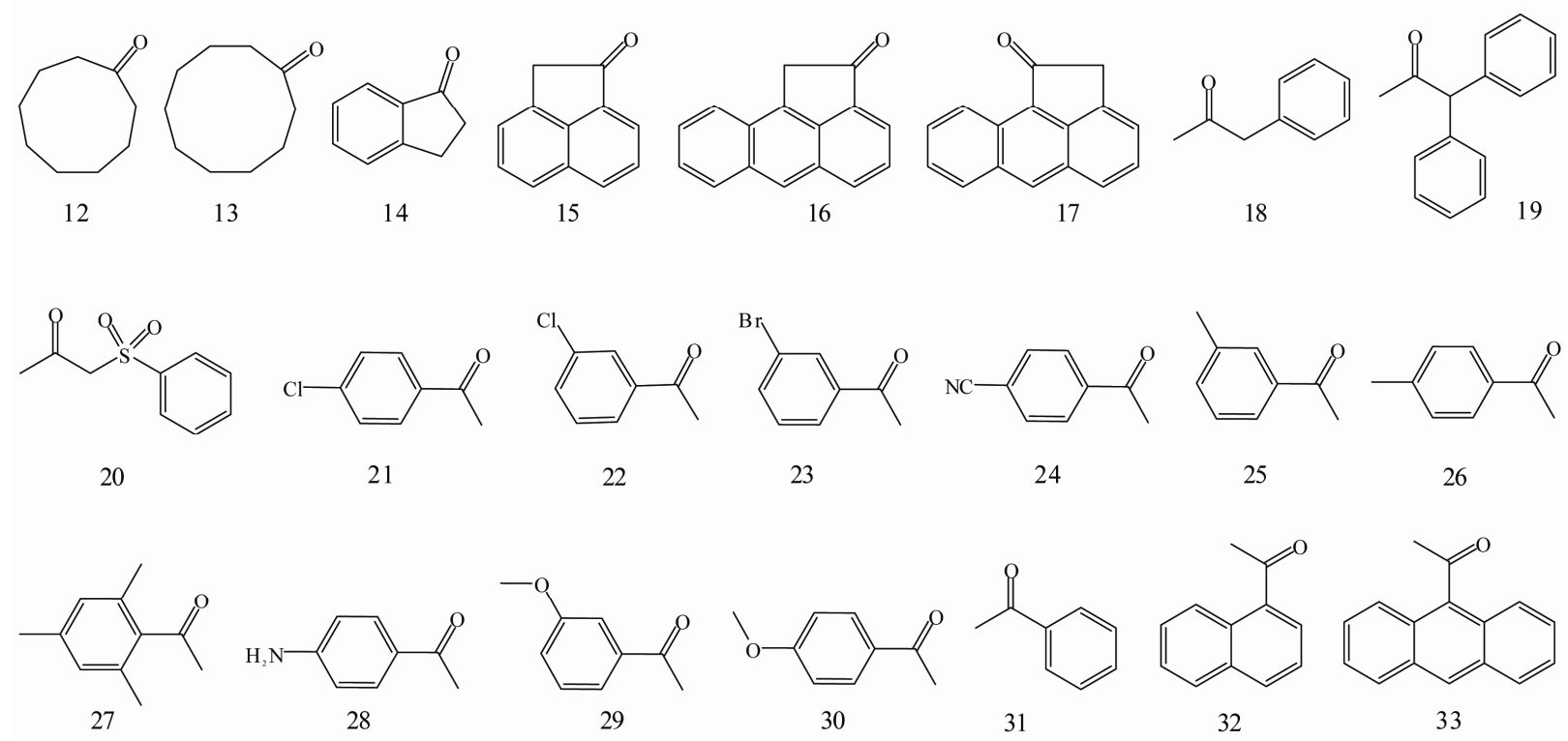<smiles>CCC(=O)c1ccccc1</smiles><smiles>COCC(=O)c1ccccc1CC(=O)c1ccccc1CC(=O)c1ccccc1</smiles><smiles>CS(=O)(=O)c1ccc2ccccc2c1CC(=O)c1ccccc1CC(=O)c1ccc2ccc3ccccc3c2c1</smiles><smiles>O=C(Cc1ccc2ccccc2c1)c1ccccc1</smiles><smiles>CC(C)C(=O)c1ccccc1</smiles>

Figure 2. Structures of the ketones employed in this study. 


\section{RESULTS AND DISCUSSION}

\subsection{QSPR Model Building}

A QSPR model for predicting the $\mathrm{p} K_{\mathrm{a}}$ of ketones in DMSO was generated using the method described above by utilizing the fifty ketones in the training set:

$$
\begin{aligned}
\mathrm{p} K_{\mathrm{a}}= & -15.95 \times \text { Hmin }-6.931 \times \mathrm{SdssC} \_\mathrm{acnt}+5.091 \\
\times & \mathrm{Qv}-23.49 \times \text { MaxNeg }-1.434 \times \text { nelem } \\
+ & 29.0743 \\
& \left(\mathrm{n}=50, r^{2}=0.86, q^{2}=0.80, s=1.92\right. \\
& F=54.19, P=2.3 \mathrm{E}-5)
\end{aligned}
$$

where Hmin is an atom-type electrotopological state (Estate) descriptor encoding the minimum hydrogen E-state value (HS) in a molecule [27]. The calculation of a HS $\left(\mathrm{HS}_{\mathrm{i}}\right)$ is given as follows:

$$
\mathrm{HS}_{\mathrm{i}}=0.2+\left(\delta_{\mathrm{i}}^{\mathrm{v}}-\delta_{\mathrm{i}}\right) / \mathrm{N}^{2}-\sum_{\mathrm{j}}\left[\left(\mathrm{I}_{\mathrm{j}}-\mathrm{I}_{\mathrm{i}}\right) / \mathrm{r}_{\mathrm{ij}}^{2}\right]
$$

where $\delta^{v}$ is all the valence electrons associated with the atom $\mathrm{i} ; \delta$ is the non-hydrogen bonded sigma electron count; $\mathrm{N}$ is the principal quantum number; the intrinsic state value $\mathrm{I}$ is defined as:

$$
\mathrm{I}=\left[(2 / \mathrm{N})^{2} \cdot \delta^{\mathrm{v}}+1\right] / \delta
$$

The HS tends to be the smallest for hydrogen which is bonded to an element of low electronegativity. $\mathrm{SdssC}$ acnt is an atom-type count that represents the number of all non-aromatic $\mathrm{sp}^{2}$ hybridized carbons $(=\mathrm{C}<)$ in the molecule (such as $\mathrm{O}=\mathrm{C}<, \mathrm{S}=\mathrm{C}<$ ). Qv is a whole-molecule $\mathrm{E}$ state polarity index that decreases as the polarity increases [27]. It encodes the existence of heteroatoms and polar functional groups and is given by:

$$
\mathrm{QV}=\sum_{\mathrm{i}} \mathrm{I}_{\mathrm{i}}^{\max } \cdot \sum_{\mathrm{i}} \mathrm{I}_{\mathrm{i}}^{\text {alkane }} /\left(\sum_{\mathrm{i}} \mathrm{I}_{\mathrm{i}}\right)^{2}
$$

where $I_{i}^{\max }=$ the intrinsic state value of the atom where the following replacements have been made: 1) all terminal atoms replaced by -F; 2) all divalent atoms replaced by -O-; 3) all trivalent atoms replaced by $>\mathrm{N}-$; 4) all quaternary atoms replaced by $>\mathrm{C}<$. MaxNeg reflects the largest partial negative charge over the atoms in a molecule. Nelem is the total number of different elements in the molecule.

The statistical parameters that describe the quality of the regression Eq.1 such as squared correlation coefficient $\left(r^{2}\right)$, predictive squared correlation coefficient $\left(q^{2}\right)$, standard error of estimation $(s)$, Fisher's $F$-value using the $F$ statistic $(F)$, and $P$-value using the $F$ statistic $(P)$ are given below Eq.1.

As shown in the plot of the calculated $\mathrm{p} K_{\mathrm{a}}$ against experimental $\mathrm{p} K_{\mathrm{a}}$ (Figure 3), Eq.1 poorly predicted the $\mathrm{p} K_{\mathrm{a}}$ of four ketones, which are $\mathbf{2 8}, \mathbf{3 7}, \mathbf{3 9}$, and $\mathbf{5 2}$, especially for ketone 39, with an absolute residual between the prediction and experimental data of nearly $6 \log$ units. There

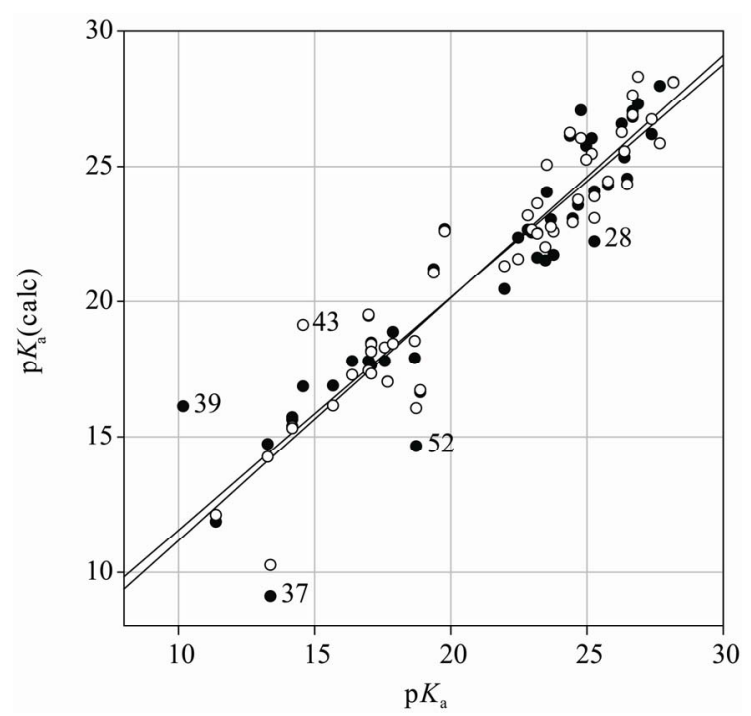

Figure 3. Plot of calculated $\mathrm{p} K_{\mathrm{a}}$ vs. experimental $\mathrm{p} K_{\mathrm{a}}$ for Eq.1 (•) and Eq.2 (०).

are two ketones containing cyano groups, 24 and 39. The influence of the cyano group on the acidity of $\mathbf{3 9}$ is more profound than it is on $\mathbf{2 4}$, since the cyano group is directly attached to the methylene group in $\mathbf{3 9}$. However, among the five descriptors, only Hmin partially reflected this distance difference between the cyano group and the alpha hydrogen atoms. This could be the cause of poor acidity prediction for 39 . Since these descriptors are favorable for most of the members in the TSET, a second model was thus built without ketone $\mathbf{3 9}$ to test this hypothesis by using the same method mentioned above to give Eq.2:

$$
\begin{aligned}
\mathrm{p} K_{\mathrm{a}}= & -12.46 \times \mathrm{Hmin}-6.337 \times \mathrm{SdssC} \mathrm{acnt}+7.187 \\
\times & \mathrm{Qv}-23.43 \times \mathrm{MaxNeg}-2.634 \times \mathrm{xc3} \\
+ & 21.2905 \\
& \left(\mathrm{n}=49, r^{2}=0.90, q^{2}=0.85, s=1.58\right. \\
& F=74.54, P=1.6 \mathrm{E}-5)
\end{aligned}
$$

where $\mathrm{xc} 3$ is the simple 3 rd order chi cluster connectivity index and it is defined for a single branch point ("Y" type) and encodes the number and branching environments of such points [28]. For example, acetone (1) has only one such a branching point, whereas 3,3-dimethylbutan-2-one (2) has five. A more detailed illustration of the $\mathrm{xc} 3$ calculation is found in Figure $\mathbf{4}$ for ketones $\mathbf{1}$ and 2.

By leaving out ketone 39, not only the $r^{2}$ value is improved, but more importantly, the cross-validation indicated a more robust model. However, the prediction of ketone $\mathbf{4 3}$ by Eq.2 was far from acceptable, with a residual of $-4.5 \log$ units (Figure 3 ). The nitrogen atom in the pyridine ring of $\mathbf{4 3}$ has the same electron-withdrawing effect as a nitro group, but none of the five descriptors can reveal this feature. Additionally, the absolute $t$ - 


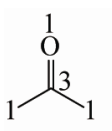

1

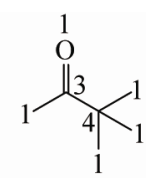

2
Figure 4. Illustration of the $\mathrm{xc} 3$ descriptor calculation. The digit $(\delta)$ near each atom indicates the number of non-hydrogen atoms that is attached to it. The xc3 descriptor for each molecule is then calculated by the following function: $\mathrm{xc} 3=\sum\left(\delta_{\mathrm{i}} \delta_{\mathrm{j}} \delta_{\mathrm{k}} \delta_{\mathrm{l}}\right)^{-0.5}$. For ketone 1, xc3 $=(1 \times$ $3 \times 1 \times 1)^{-0.5}=0.57735$, whereas for ketone 2 , $\mathrm{xc} 3=(1 \times 3 \times 1 \times 4)^{-0.5}+(1 \times 1 \times 4 \times 1)^{-0.5}+$ $(1 \times 1 \times 4 \times 3)^{-0.5}+(1 \times 1 \times 4 \times 3)^{-0.5}+(1 \times 1 \times$ $4 \times 3)^{-0.5}=1.6547$.

statistic values for both MaxNeg and xc3 in Eq.2 are below 3.5 (data not shown). This is important because the $t$-statistic indicates the significance of each individual descriptor in the linear regression equation. A third model (Eq.3) was thus built after leaving out $\mathbf{4 3}$ to improve the $t$-statistic by following the same procedure stated above as:

$$
\begin{gathered}
\mathrm{p} K_{\mathrm{a}}=-11.42 \times \operatorname{Hmin}-6.365 \times \mathrm{SdssC} \_\mathrm{acnt}+7.487 \times \mathrm{Qv} \\
-3.274 \times \mathrm{xc3}-24.12 \times \operatorname{MaxNeg}+20.5577 \\
\left(\mathrm{n}=48, r^{2}=0.91, q^{2}=0.86, s=1.42\right. \\
F=89.54, P=3.6 \mathrm{E}-6)
\end{gathered}
$$

Although there was not much difference for $r^{2}$ and $q^{2}$ between Eq.2 and Eq.3, the $F$ statistic is modestly improved along with the $t$-statistic for each descriptor (Table 1). Among the five descriptors, the $|t|$ values for Hmin, SdssC_acnt and Qv are each above 4.0 and all $|t|$ values are $\geq 3.5$, which implies that these descriptors contribute significantly to the model. Furthermore, to check the validity of the selected descriptor set (Hmin, SdssC_acnt, Qv, xc3, and MaxNeg), 100 randomizations of the dependent variable values among the training set were carried out. Values of the multiple $r^{2}$ were computed for each of corresponding regressions. The mean of $r^{2}$ was 0.11 . The mean square deviation of $r^{2}$ value was 0.058 , indicating that the model was not arrived at merely by chance.

High $F$, low $s$, a $P$ value near 0 , and $r^{2}$ and $q^{2}$ values near 1 all indicate a reasonable QSPR model. In general, a QSPR model is considered significant when $P<0.001$ [29]. The established QSPR model (Eq.3) thus shows a significant statistical quality, both in a reliability $\left(r^{2}=\right.$ $0.91)$ and a predictability $\left(q^{2}=0.86\right)$. The following discussion will therefore focus only on Eq.3.

A correlation plot of the calculated $\mathrm{p} K_{\mathrm{a}}$ against experimental $\mathrm{p} K_{\mathrm{a}}$ for Eq.3 is shown in Figure 5. The calculated $\mathrm{p} K_{\mathrm{a}}$ values for each ketone in the TSET and correlation matrix for the five descriptors can be found in Tables 2 and 3 respectively. The absolute value of the highest intercorrelation coefficient between any two of the five descriptors in Table 3 is 0.6345 (Hmin to xc3), which is below 0.7. As shown in Table 2, the residuals between calculated $\mathrm{p} K_{\mathrm{a}}$ and experimental $\mathrm{p} K_{\mathrm{a}}$ for over $70 \%$ of the TSET (thirty-four ketones out of forty-eight in total) are smaller than standard error of estimation. In general, the equation gave better prediction for group $\mathrm{C} 2$ $\left(\mathrm{CH}_{3} \mathrm{COR}\right)$, followed by group $\mathrm{B}$ (cyclic ketones) and group $\mathrm{C} 3\left(\mathrm{PhCOCH}_{2} \mathrm{R}\right)$. This is not surprising since the group sizes of these three groups are much larger than others, which let them take a leading role in selecting descriptors that are more favorable for them. In most of the groups, $\mathrm{p} K_{\mathrm{a}}$ values for ketones that show a distinguishable structure than other members are not very well predicted by the model (e.g. ketones 2, 15, and 28). In addition, it seems that the effect of substitutions is not additive: if two identical functional groups are present in a molecule, the $\mathrm{p} K_{\mathrm{a}}$ doesn't simply change twice as much compared to a molecule containing only one of such. This is illustrated by the two series of ketones $\mathbf{1} \rightarrow \mathbf{1 8} \rightarrow$ 55 and $3 \rightarrow 38 \rightarrow 37$.

\subsection{Interpretation of Ketone Acidity}

As pointed out by Bordwell et al. [25], acidity changes observed for ketones by different substituents are mainly

Table 1. Mean, standard deviation (SD) and $t$-statistic $(t)$ for variables in Eq.3.

\begin{tabular}{ccccccc}
\hline & $\mathrm{p} K_{\mathrm{a}}$ & $\mathrm{Qv}$ & MaxNeg & $\mathrm{xc3}$ & SdssC_acnt & Hmin \\
\hline Mean & 21.67 & 1.13 & -0.419 & 0.798 & 1.064 & 0.701 \\
$\mathrm{SD}$ & 4.47 & 0.19 & 0.0370 & 0.339 & 0.247 & 0.227 \\
$t$ & $\mathrm{NA}^{\mathrm{a}}$ & 4.62 & -3.472 & -3.557 & -7.467 & -7.474 \\
\hline
\end{tabular}

${ }^{\mathrm{a}} \mathrm{NA}=$ Not applicable.

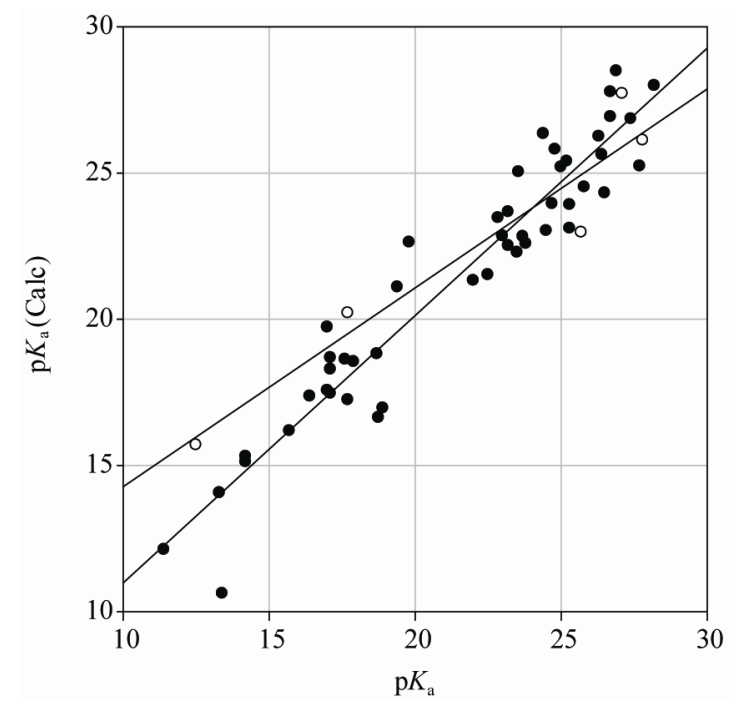

Figure 5. Plot of calculated $\mathrm{p} K_{\mathrm{a}}$ (Eq.3) vs. experimental $\mathrm{p} K_{\mathrm{a}}$ for training set $(\bullet)$ and predicting set $(\circ)$. 
Table 2. Calculated descriptor and $\mathrm{p} K_{\mathrm{a}}$ values (Eq.3) for ketones employed in this study.

\begin{tabular}{|c|c|c|c|c|c|c|c|c|c|c|}
\hline \multicolumn{2}{|c|}{ Compd. } & \multirow{2}{*}{$\begin{array}{c}\text { Qv } \\
1.18837\end{array}$} & \multirow{2}{*}{$\begin{array}{c}\text { MaxNeg } \\
-0.363773\end{array}$} & \multirow{2}{*}{$\begin{array}{c}\mathrm{xc} 3 \\
0.57735\end{array}$} & \multirow{2}{*}{$\begin{array}{c}\text { SdssC_acnt } \\
1\end{array}$} & \multirow{2}{*}{$\begin{array}{c}\text { Hmin } \\
0.495833\end{array}$} & \multirow{2}{*}{$\begin{array}{c}\mathrm{p} K_{\mathrm{a}}(\mathrm{calc}) \\
24.3131\end{array}$} & \multirow{2}{*}{$\frac{\mathrm{p} K_{\mathrm{a}}(\exp )}{26.5}$} & \multirow{2}{*}{$\begin{array}{c}\text { Residual } \\
2.187\end{array}$} & \multirow{2}{*}{$\begin{array}{c}\text { Set Type } \\
\text { TSET }\end{array}$} \\
\hline A & 1 & & & & & & & & & \\
\hline & 2 & 1.71171 & -0.362911 & 1.6547 & 1 & 0.447569 & 25.2345 & 27.7 & 2.466 & TSET \\
\hline & 3 & 0.921785 & -0.362257 & 0.816497 & 2 & 0.589958 & 14.0578 & 13.3 & -0.7578 & TSET \\
\hline & 4 & 0.910359 & -0.362154 & 0.696923 & 2 & 0.523632 & 15.1185 & 14.2 & -0.9185 & TSET \\
\hline & 5 & 1.38932 & -0.363201 & 0.288675 & 1 & 0.411125 & 27.7148 & 27.1 & -0.6148 & PSET \\
\hline & 6 & 1.72295 & -0.362625 & 0.859117 & 1 & 0.441347 & 27.9874 & 28.2 & 0.2126 & TSET \\
\hline \multirow[t]{11}{*}{$\mathrm{B}$} & 7 & 0.926293 & -0.363181 & 0.288675 & 1 & 0.440625 & 23.912 & 25.3 & 1.388 & TSET \\
\hline & 8 & 1.04132 & -0.363182 & 0.288675 & 1 & 0.462847 & 24.5195 & 25.8 & 1.28 & TSET \\
\hline & 9 & 1.13987 & -0.363182 & 0.288675 & 1 & 0.430569 & 25.6259 & 26.4 & 0.7741 & TSET \\
\hline & 10 & 1.22499 & -0.363182 & 0.288675 & 1 & 0.443069 & 26.1192 & 27.8 & 1.6808 & PSET \\
\hline & 11 & 1.29913 & -0.363182 & 0.288675 & 1 & 0.427722 & 26.8508 & 27.4 & 0.5492 & TSET \\
\hline & 12 & 1.42173 & -0.363182 & 0.288675 & 1 & 0.427536 & 27.7709 & 26.7 & -1.071 & TSET \\
\hline & 13 & 1.51875 & -0.363182 & 0.288675 & 1 & 0.428395 & 28.4874 & 26.9 & -1.587 & TSET \\
\hline & 14 & 0.992438 & -0.444381 & 0.538452 & 1 & 0.677375 & 22.845 & 23 & 0.155 & TSET \\
\hline & 15 & 0.979818 & -0.449867 & 0.816229 & 1 & 0.874486 & 19.723 & 17 & -2.723 & TSET \\
\hline & 16 & 1.01571 & -0.452228 & 1.08839 & 1 & 0.951111 & 18.2827 & 17.1 & -1.183 & TSET \\
\hline & 17 & 1.01571 & -0.452207 & 1.09401 & 1 & 0.92667 & 18.5429 & 17.9 & -0.6429 & TSET \\
\hline \multirow[t]{3}{*}{$\mathrm{C} 1$} & 18 & 1.13081 & -0.363127 & 0.612372 & 1 & 0.594142 & 22.6294 & 19.8 & -2.829 & TSET \\
\hline & 19 & 1.14996 & -0.362471 & 0.777778 & 1 & 0.692451 & 21.093 & 19.4 & -1.693 & TSET \\
\hline & 20 & 0.817223 & -0.360885 & 1.60306 & 1 & 0.706621 & 15.6978 & 12.5 & -3.1978 & PSET \\
\hline \multirow[t]{13}{*}{$\mathrm{C} 2$} & 21 & 1.03258 & -0.440311 & 0.788675 & 1 & 0.646047 & 22.5859 & 23.8 & 1.214 & TSET \\
\hline & 22 & 1.03258 & -0.440311 & 0.788675 & 1 & 0.652433 & 22.513 & 23.2 & 0.687 & TSET \\
\hline & 23 & 1.14927 & -0.448196 & 0.788675 & 1 & 0.644333 & 23.6693 & 23.2 & -0.4693 & TSET \\
\hline & 24 & 1.04142 & -0.457447 & 0.788675 & 1 & 0.642647 & 21.3198 & 22 & 0.6802 & TSET \\
\hline & 25 & 1.22222 & -0.444696 & 0.788675 & 1 & 0.550583 & 25.2015 & 25 & -0.2015 & TSET \\
\hline & 26 & 1.22222 & -0.444696 & 0.788675 & 1 & 0.532923 & 25.4031 & 25.2 & -0.2031 & TSET \\
\hline & 27 & 1.50044 & -0.439044 & 1.20452 & 1 & 0.548923 & 25.8057 & 24.8 & -1.006 & TSET \\
\hline & 28 & 1.04142 & -0.457447 & 0.788675 & 1 & 0.642647 & 23.1043 & 25.3 & 2.196 & TSET \\
\hline & 29 & 1.09917 & -0.435697 & 0.704124 & 1 & 0.665776 & 23.0247 & 24.5 & 1.475 & TSET \\
\hline & 30 & 1.09917 & -0.428801 & 0.704124 & 1 & 0.655976 & 22.9683 & 25.7 & 2.7317 & PSET \\
\hline & 31 & 1.0651 & -0.439062 & 0.5 & 1 & 0.628361 & 23.9463 & 24.7 & 0.7537 & TSET \\
\hline & 32 & 1.09295 & -0.445689 & 0.772166 & 1 & 0.680545 & 22.8278 & 23.7 & 0.8722 & TSET \\
\hline & 33 & 1.10829 & -0.448904 & 1.04994 & 1 & 0.732728 & 21.515 & 22.5 & 0.985 & TSET \\
\hline \multirow[t]{12}{*}{$\mathrm{C} 3$} & 34 & 1.13081 & -0.43878 & 0.402369 & 1 & 0.488934 & 26.343 & 24.4 & -1.943 & TSET \\
\hline & 35 & 1.05257 & -0.438425 & 0.606493 & 1 & 0.915111 & 20.2119 & 17.7 & -2.5119 & PSET \\
\hline & 36 & 1.09714 & -0.444395 & 0.606493 & 1 & 0.775684 & 22.2841 & 23.5 & 1.216 & TSET \\
\hline & 37 & 0.908075 & -0.443194 & 0.804738 & 2 & 1.05672 & 10.6166 & 13.4 & 2.783 & TSET \\
\hline & 38 & 0.917396 & -0.443207 & 0.810617 & 2 & 0.650357 & 15.3071 & 14.2 & -1.107 & TSET \\
\hline & 40 & 0.830623 & -0.44186 & 1.59718 & 1 & 1.20175 & 12.1195 & 11.4 & -0.7195 & TSET \\
\hline & 41 & 1.25082 & -0.443047 & 0.810617 & 1 & 0.573968 & 25.037 & 23.55 & -1.487 & TSET \\
\hline & 42 & 1.02249 & -0.441973 & 0.402369 & 1 & 0.676746 & 23.4647 & 22.85 & -0.6147 & TSET \\
\hline & 44 & 1.08644 & -0.438425 & 1.27316 & 1 & 0.996096 & 17.3608 & 16.4 & -0.9608 & TSET \\
\hline & 45 & 1.08644 & -0.438425 & 1.14395 & 1 & 1.06836 & 16.9588 & 18.9 & 1.941 & TSET \\
\hline & 46 & 1.08644 & -0.438425 & 1.21199 & 1 & 0.996096 & 17.5611 & 17 & -0.5611 & TSET \\
\hline & 47 & 1.08644 & -0.438425 & 1.21199 & 1 & 1.00519 & 17.4573 & 17.1 & -0.3573 & TSET \\
\hline \multirow[t]{4}{*}{$\mathrm{C} 3$} & 48 & 1.08644 & -0.438425 & 1.14395 & 1 & 1.04392 & 17.2378 & 17.7 & 0.4622 & TSET \\
\hline & 49 & 1.08031 & -0.438425 & 1.42734 & 1 & 1.05132 & 16.1796 & 15.7 & -0.4796 & TSET \\
\hline & 50 & 1.0727 & -0.438425 & 0.871785 & 1 & 0.991736 & 18.6218 & 17.6 & -1.022 & TSET \\
\hline & 51 & 1.0727 & -0.438425 & 0.939826 & 1 & 0.967295 & 18.6781 & 17.1 & -1.578 & TSET \\
\hline \multirow[t]{3}{*}{$\mathrm{C} 4$} & 52 & 1.08506 & -0.43778 & 0.803561 & 1 & 1.19256 & 16.6292 & 18.75 & 2.121 & TSET \\
\hline & 53 & 1.26181 & -0.444132 & 0.69245 & 1 & 0.511156 & 26.2495 & 26.3 & 0.05051 & TSET \\
\hline & 54 & 1.2096 & -0.444113 & 0.525783 & 1 & 0.465708 & 26.9227 & 26.7 & -0.2227 & TSET \\
\hline $\mathrm{C} 5$ & 55 & 1.09714 & -0.36248 & 0.696923 & 1 & 0.880892 & 18.8109 & 18.7 & -0.1109 & TSET \\
\hline
\end{tabular}


Table 3. Correlation matrix ( $r$ values) for descriptors in Eq.3.

\begin{tabular}{ccccccc}
\hline & $\mathrm{p} K_{\mathrm{a}}$ & $\mathrm{Qv}$ & MaxNeg & $\mathrm{xc3}$ & SdssC_acnt Hmin \\
\hline $\mathrm{p} K_{\mathrm{a}}$ & 1 & & & & & \\
$\mathrm{Qv}$ & 0.628 & 1 & & & & \\
MaxNeg & 0.2247 & 0.3353 & 1 & & & \\
$\mathrm{xc3}$ & -0.5299 & 0.0181 & -0.3723 & 1 & & \\
SdssC_acnt & -0.4585 & -0.3003 & 0.21 & -0.01812 & 1 & \\
Hmin & -0.7548 & -0.4545 & -0.5028 & 0.6345 & -0.1316 & 1 \\
\hline
\end{tabular}

a balance among three effects: 1) steric effect on resonance and solvation of the anion; 2) stabilizing effect on the enolate ion either through delocalization or induction; and 3 ) lone-pair-lone-pair electron repulsions.

Among the five descriptors in Eq.3, Qv is positively correlated with $\mathrm{p} K_{\mathrm{a}}$, and the other four descriptors contribute negatively to the $\mathrm{p} K_{\mathrm{a}}$ value, especially Hmin. Being developed to encode both the electronic and steric attributes of atoms in a molecule, two indices might be expected to successfully capture the features influencing $\mathrm{p} K_{\mathrm{a}}$ as noted in the previous paragraph. Indeed, the Estate index Hmin was selected as one of the most significant descriptors in the model. As shown in Table 2, except for 44 and 46, the ketones have unique Hmin values. Furthermore, Hmin is significantly inversely correlated with $\mathrm{p} K_{\mathrm{a}}$ (Table 3) and ketones that have Hmin values larger than 0.8 (e.g. 15 - 17, 37, 40, etc.) tend to be more acidic (observed $\mathrm{p} K_{\mathrm{a}}$ values are among 11.4 to 18.9). Therefore these compounds are well predicted. A more specific example could be illustrated by comparing 21 to 22. Having identical values for the other four descriptors, the differences in their Hmin properties decided the variations in their $\mathrm{p} K_{\mathrm{a}}$ values. The meta-chloro group in $\mathbf{2 2}$ generates a stronger induced electron withdrawing effect on the enolate ion than the para-chloro group in $\mathbf{2 1}$ does, and hence $\mathbf{2 2}$ is more acidic than 21. The steric effect reflected by Hmin is exemplified by comparing 16 to 17 (although 16 and 17 don't have exactly matching MaxNeg and xc3 values, the role of both descriptors is quite insignificant comparing to Hmin, in this case). As suggested by their 3D structures, atoms $\mathrm{C} 2$, $\mathrm{C} 2 \mathrm{a}$ and $\mathrm{C} 3$ are not in the same plane as the C4-C10 atoms, and this generates a more hindered environment for the methylene group in $\mathbf{1 7}$ than the one in 16. Since steric effect contributes negatively to the acidity, $\mathbf{1 6}$ is more acidic than 17. On the other hand, Hmin seemed not sufficient to evaluate the acidity of polycyclic aromatic ketones. For example, although 48 is more acidic than 45, 45 shows a higher Hmin value than 48 in spite of the fairly strong inverse relationship between $\mathrm{p} K_{\mathrm{a}}$ and Hmin (see Table 2).

The impact of SdssC_acnt on ketones acidities can be easily observed for $\mathbf{3}-\mathbf{4}$ and $\mathbf{3 7}$ - $\mathbf{3 8}$ compared to the rest of the ketones. The SdssC_acnt values for these four ke- tones are 2, two times of those for other ketones (Table 2), which makes them quite acidic as demonstrated by the lower $\mathrm{p} K_{\mathrm{a}}$ of $\mathbf{3}$ and $\mathbf{3 8}$ than $\mathbf{1}$ and $\mathbf{3 1}$ respectively. This was due to the additional electron withdrawing effect contributed by the second carbonyl group.

Not surprisingly, geometric and positional isomers have the same Qv values (for example, 44 - 48). Among the forty-eight ketones, only 3 - 4, 7, 37 - 38, and 40 have Qv values less than 0.95 . It is not difficult to understand that $3-\mathbf{4}$, and $37-38$ are more polar due to the presence of second carbonyl groups. Similarly, the sulfonyl group in $\mathbf{4 0}$ makes the molecule more polar. These moieties are electron-withdrawing groups, which have a stabilizing effect on the enolate ion through their inductive stabilizing effect, and therefore the ketones containing these moieties are more acidic. Cyclobutanone 7 is the most polar compound in the aliphatic cycloketones category, and has the lowest $\mathrm{p} K_{\mathrm{a}}$ amongst them. On the other hand this descriptor as well as others would not be able to distinguish among different conformation of ketones (such as cis vs. trans, chair vs. boat) and its influence to the acidity of the ketones.

Descriptor xc3 is an indicator of the degree of third order branching, and thus implicates the effect of substitution in a molecule. A molecule that is relatively compact at some point(s) will have a higher xc3 value. There are eleven ketones of which xc3 values are larger than 1 in the TSET. A critical aspect will have to be considered when xc3 is involved to explain the acidities of ketones in addition to the hindrance effect it causes, that is, whether the branching at certain position(s) can stabilize the enolate ion. This factor is perfectly demonstrated by ketones 16 - 17, 44 - 49 and 40. The enolate ion for ketone $\mathbf{4 0}$ is stabilized through inducing effect by sulfonyl group, whereas the delocalization of the anion (the negative charge is distributed to the phenyl rings through resonance) is achieved for ketones 16 - 17 and 44 - 49. In contrast, the increased branching in ketone 2 can't attain either of the above effects, and this counts for its decreased acidity, compared to the less branching counterpart 1. For ketone 2, the steric hindrance for the solvation of its anion is the determining factor for $\mathrm{p} K_{\mathrm{a}}$.

MaxNeg is a charge index. Most of the ketones carry similar MaxNeg values. Interestingly, no matter what the size of the cycloketones is, they share the same MaxNeg value. More importantly, the MaxNeg values for ketones in which the carbonyl groups are directly attached to a phenyl ring are around -0.44 . The MaxNeg values for the remaining ketones are approximately -0.36 . The repulsion between the negatively charged carbonyl oxygen and the aromatic pi-bonds, which is unfavorable for the stability of the enolate ion, might be the reason that MaxNeg contributes negatively to the $\mathrm{p} K_{\mathrm{a}}$ of the ketones, a similar effect that lone-pair-lone-pair electron repul- 
sions have.

\subsection{Ketone Acidity Prediction}

To further validate the built QSPR model, the generated regression Eq.3 was used to predict the $\mathrm{p} K_{\mathrm{a}}$ of the five ketones in the external prediction set (Table 2). A correlation plot of the calculated $\mathrm{p} K_{\mathrm{a}}$ against experimental $\mathrm{p} K_{\mathrm{a}}$ for the PSET is shown in Figure 5. A linear regression was performed for the calculated $\mathrm{p} K_{\mathrm{a}}$ and the experimental $\mathrm{p} K_{\mathrm{a}}$. The statistics $r^{2}$ and $s$ are 0.92 and 1.618 respectively, which was considered to be satisfactory. Table 2 showed that the QSPR model estimated the acidity for those ketones with acceptable values while the best prediction was obtained for compound 5. Compound $\mathbf{2 0}$ is one of the only two ketones that carry a sulfonyl group, providing an explanation for the relatively poor prediction.

The $\mathrm{p} K_{\mathrm{a}}$ shows a parabolic relationship with the ring size of cycloketones $4-9$, with the $\mathrm{p} K_{\mathrm{a}}$ of cycloheptanone 10 being the highest. However, cycloheptanone 10 wasn't in the TSET when the model was built to reveal this characteristic and hence none of the five descriptors in the QSPR model Eq.3 can actually reflect this particular feature of cycloketones. Having a small number of members among the whole training set also likely confounded the prediction of the relative acidities of ketones in this series, although the residuals for most cycloketones are acceptable.

\section{CONCLUSION}

Ketones are important in both biochemistry and organic chemistry, and information about their $\mathrm{p} K_{\mathrm{a}}$ properties will be beneficial for both biologists and chemists. The direct measurements of $\mathrm{p} K_{\mathrm{a}}$ of ketones are not available due to their extremely weak acidity. Hence, a QSPR model which can be used to predict the acidities of ketones is highly desirable. Fifty-five ketones of which the $\mathrm{p} K_{\mathrm{a}}$ in DMSO were determined using the method developed by Bordwell were used to build such a QSPR model. By leaving out two ketones (39 and 43) that show unique structures from others, the training set of fortyeight ketones in three main classes covering most functional groups with an overall $\mathrm{p} K_{\mathrm{a}}$ in DMSO ranging from 11.4 to 28.2 is very well described by the statistically significant regression Eq.3 $\left(r^{2}=0.91, q^{2}=0.86, s=\right.$ 1.42). Steps have been taken to ensure the quality of the generated QSPR model in this paper. Importantly, the five descriptors used to build the model are largely chemically intuitive and in agreement with the proposed theory that describes the acidity of ketones, which further strengthened the significance of the model. Moreover, the QSPR model can reasonably predict the acidity of the five ketones in the external prediction set $\left(r^{2}=0.92, s=\right.$
1.618). We anticipate that the model obtained will be useful for prediction of ketone acidity that may be related to their reactivity, reaction mechanism, and possibly some biophysical properties in biological systems.

\section{ACKNOWLEDGEMENTS}

The authors thank Dr. Lemont B. Kier for his kind encouragement and guidance during the study. Dr. Y. Y. would like to acknowledge the Department of Medicinal Chemistry, Virginia Commonwealth University for providing excellent learning experience for all the postdoctoral fellows.

\section{REFERENCES}

[1] Krebs, H.A. (1961) The physiological role of ketone bodies. Biochemical Journal, 80, 225-233.

[2] Henderson, S.T. (2010) Ketone bodies as a therapeutic for Alzheimer's disease. RSC Drug Discovery Series, 2, 275306.

[3] Kashiwaya, Y., Takeshima, T., Mori, N., Nakashima, K., Clarke, K. and Veech, R.L. (2000) D- $\beta$-Hydroxybutyrate protects neurons in models of Alzheimer's and Parkinson's disease. Proceedings of the National Academy of Sciences of the United States of America, 97, 5440-5444. doi:10.1073/pnas.97.10.5440

[4] Cornille, E., Abou-Hamdan, M., Khrestchatisky, M., Henderson, S.T., Nieoullon, A., De Reggi, M. and Gharib, B. (2010) Enhancement of L-3-hydroxybutyryl-CoA dehydrogenase activity and circulating ketone body levels by pantethine. Relevance to dopaminergic injury. $B M C$ Neuroscience, 11, 51. doi:10.1186/1471-2202-11-51

[5] Hasebe, N., Abe, K., Sugiyama, E., Hosoi, R. and Inoue, O. (2010) Anticonvulsant effects of methyl ethyl ketone and diethyl ketone in several types of mouse seizure models. European Journal of Pharmacology, 642, 66-71. doi:10.1016/j.ejphar.2010.05.036

[6] Hauptman, J.S. (2010) From the bench to the bedside: Breaking down the blood-brain barrier, decoding the habenula, understanding hand choice, and the role of ketone bodies in epilepsy. Surgical Neurology International, 1, 86. doi:10.4103/2152-7806.74143

[7] Sawai, M., Yashiro, M., Nishiguchi, Y., Ohira, M. and Hirakawa, K. (2004) Growth-inhibitory effects of the ketone body, Monoacetoacetin, on human gastric cancer cells with succinyl-CoA: 3-oxoacid CoA-transferase (SCOT) deficiency. Anticancer Research, 24, 2213-2217.

[8] Novak, M. and Loudon, G.M. (1977) The $\mathrm{p} K_{\mathrm{a}}$ of acetophenone in aqueous solution. Journal of Organic Chemistry, 42, 2494-2498. doi:10.1021/jo00434a032

[9] Chiang, Y., Kresge, A.J., Tang, Y.S. and Wirz, J. (1984) The $\mathrm{p} K_{\mathrm{a}}$ and keto-enol equilibrium constant of acetone in aqueous solution. Journal of the American Chemical Society, 106, 460-462. doi:10.1021/ja00314a055

[10] Chiang, Y., Kresge, A.J. and Wirz, J. (1984) Flash-photolytic generation of acetophenone enol. The ketoenol equilibrium constant and $\mathrm{p} K_{\mathrm{a}}$ of acetophenone in aqueous 
solution. Journal of the American Chemical Society, 106, 6392-6395. doi:10.1021/ja00333a049

[11] Pollack, R.M., Mack, J.P.G. and Eldin, S. (1987) Direct observation of a dienolate intermediate in the base-catalyzed isomerization of 5-androstene-3,17-dione to 4-androstene-3,17-dione. Journal of the American Chemical Society, 109, 5048-5050. doi:10.1021/ja00250a061

[12] Bordwell, F.G. (1988) Equilibrium acidities in dimethyl sulfoxide solution. Accounts of Chemical Research, 21, 456-463. doi:10.1021/ar00156a004

[13] Bordwell, F.G. and Bausch, M.J. (1986) Radical cation acidities in dimethyl sulfoxide solution. Journal of the American Chemical Society, 108, 2473-2474. doi:10.1021/ja00269a071

[14] Bordwell, F.G., Cheng, J.P., et al. (1988) Homolytic bond dissociation energies in solution from equilibrium acidity and electrochemical data. Journal of the American Chemical Society, 110, 1229-1231. doi:10.1021/ja00212a035

[15] Lowry, T.H. and Richardson, K.S. (1981) Mechanism and theory in organic chemistry. 2nd Edition, Harper and Row, New York.

[16] Alnajjar, M.S., Zhang, X.-M., Gleicher, G.J., Truksa, S.V. and Franz, J.A. (2002) Equilibrium acidities and homolytic bond dissociation energies of acidic $\mathrm{C}-\mathrm{H}$ bonds in $\alpha$-arylacetophenones and related compounds. Journal of Organic Chemistry, 67, 9016-9022. doi:10.1021/jo020275s

[17] Yu, H.-Y., Kühne, R., Ebert, R.-U. and Schüürman, G. (2010) Comparative analysis of QSAR models for predicting $\mathrm{p} K_{\mathrm{a}}$ of organic oxygen acids and nitrogen bases from molecular structure. Journal of Chemical Information and Modeling, 50, 1949-1960. doi:10.1021/ci100306k

[18] Eckert, F. and Klamt, A. (2006) Accurate prediction of basicity in aqueous solution with COSMO-RS. Journal of Computational Chemistry, 27, 11-19. doi:1002/jcc.20309

[19] Klamt, A., Eckert, F., Diedenhofen, M. and Beck, M.E. (2003) First principles calculations of aqueous $\mathrm{p} K_{\mathrm{a}}$ values for organic and inorganic acids using COSMO-RS reveal an inconsistency in the slope of the $\mathrm{p} K_{\mathrm{a}}$ scale. Journal of Physical Chemistry A, 107, 9380-9386. doi:10.1021/jp0346880

[20] Liptak, M.D. and Shields, G.C. (2001) Accurate $\mathrm{p} K_{\mathrm{a}}$ Calculations for carboxylic acids using complete basis set and Gaussian-n models combined with CPCM continuum solvation methods. Journal of the American Chemical Society, 123, 7314-7319. doi:10.1021/ja010534f

[21] Schüürman, G., Cossi, M., Barone, V. and Tomasi, J. (1998) Prediction of the $\mathrm{p} K_{\mathrm{a}}$ of carboxylic acids using the $\mathrm{ab}$ initio continuum-solvation model PCM-UAHF. Journal of Physical Chemistry A, 102, 6706-6712. doi:10.1021/jp981922f

[22] Schüürman, G. (1998) Quantum chemical analysis of the energy of proton transfer from phenol and chlorophenols to $\mathrm{H}_{2} \mathrm{O}$ in the gas phase and in aqueous solution. Journal of Chemical Physics, 109, 9523-9528. doi:10.1063/1.477614

[23] Schüürman, G. (1996) Modelling $\mathrm{p} K_{\mathrm{a}}$ of carboxylic acids and chlorinated phenols. Quantitative Structure-Activity Relationships, 15, 121-132. doi:10.1002/qsar.19960150206

[24] Bordwell, F.G. and Harrelson, J.A. Jr. (1990) Acidities and homolytic bond dissociation energies of the $\alpha \mathrm{C}-\mathrm{H}$ bonds in ketones in DMSO. Canadian Journal of Chemistry, 68, 1714-1718. doi.org/10.1139/v90-266

[25] Bordwell, F.G., Harrelson, J.A. Jr. and Zhang, X.-M. (1991) Homolytic bond dissociation energies of acidic carbon-hydrogen bonds activated by one or two electron acceptors. Journal of Organic Chemistry, 56, 4448-4450. doi.org/10.1021/jo00014a022

[26] SYBYL 8.1, Tripos International, St. Louis, USA.

[27] Kier, L. and Hall, L. (1999) Molecular structure description: The electrotopological state. Academic Press, New York.

[28] Kier, L. and Hall, L. (1986) Molecular connectivity in structure-activity analysis. Research Studies Press, Chichester.

[29] Liao, S.-Y., Xu, L.-C., Qian, L. and Zheng, K.-Ch. (2007) QSAR and action mechanism of troxacitabine prodrugs with antitumor activity. Journal of Theoretical \& Computational Chemistry, 6, 947-958. doi:10.1142/S0219633607003428 